\title{
$Y$-Function Analysis of the Low Temperature Behavior of Ultrathin Film FD SOI MOSFETs
}

\author{
A. Karsenty ${ }^{1}$ and A. Chelly ${ }^{2}$ \\ ${ }^{1}$ Department of Applied Physics, Faculty of Engineering, Jerusalem College of Technology, 91160 Jerusalem, Israel \\ ${ }^{2}$ Faculty of Engineering, Bar-Ilan University, 52900 Ramat Gan, Israel \\ Correspondence should be addressed to A. Karsenty; karsenty@jct.ac.il
}

Received 10 March 2014; Revised 30 April 2014; Accepted 6 May 2014; Published 11 June 2014

Academic Editor: Abdelkarim Mercha

Copyright (C) 2014 A. Karsenty and A. Chelly. This is an open access article distributed under the Creative Commons Attribution License, which permits unrestricted use, distribution, and reproduction in any medium, provided the original work is properly cited.

\begin{abstract}
The respective transfer characteristics of the ultrathin body (UTB) and gate recessed channel (GRC) device, sharing same $W / L$ ratio but having a channel thickness of $46 \mathrm{~nm}$, and $2.2 \mathrm{~nm}$ respectively, were measured at $300 \mathrm{~K}$ and at $77 \mathrm{~K}$. By decreasing the temperature we found that the electrical behaviors of these devices were radically opposite: if for UTB device, the conductivity was increased, the opposite effect was observed for GRC. The low field electron mobility and series resistance $R_{\mathrm{SD}}$ values were extracted using a method based on $Y$-function for both the temperatures. If $R_{\mathrm{SD}}$ low values were found for $\mathrm{UTB}$, very high values $(>1 \mathrm{M} \Omega)$ were extracted for GRC. Surprisingly, for the last device, the effective field mobility is found very low $\left(<1 \mathrm{~cm}^{2} / \mathrm{Vs}\right)$ and is decreasing by lowering the temperature. After having discussed the limits of this analysis.This case study illustrates the advantage of the $Y$ analysis in discriminating a parameter of great relevance for nanoscale devices and gives a coherent interpretation of an anomalous electrical behavior.
\end{abstract}

\section{Introduction}

The $Y$-method for parameters' extraction which was first published more than two decades ago [1] had for purpose to isolate the source/drain series resistance $\left(R_{\mathrm{SD}}=R_{\mathrm{S}}+\right.$ $R_{\mathrm{D}}$ ) influence from the intrinsic channel mobility factor. The method, which relies on combining drain current and transconductance transfer characteristics, enables reliable values of the threshold voltage $V_{T}$ [2], the low field mobility $\mu_{0}$, and the mobility attenuation coefficient $\theta_{1}$ to be obtained. With time, this method was proved to remain compatible with previously existing ones, avoiding second order derivative procedure, and therefore to be applicable for inline parametric test extraction in the microelectronics industry [3]. It was also improved to overcome the difficulties encountered by applying the conventional techniques [4] and was applied to more complex devices having an architecture of nanoscale double-gate transistors [5] and fully depleted SOI MOSFETs with high- $k$ and metal gate [6] and to devices in saturation regime [7]. This smart technique also permits the extraction of the gate voltage dependence of the series resistance [8].
The low temperature study of MOSFETs' general behavior [9-12], effective mobility [13-15], and source/drain series resistance [16] was started two decades ago while the focus of those analyses mainly remained fixed on the bulk silicon transistors. With the years, several useful models and laws were developed to treat these MOS devices. For example, a generalized law for drain current modeling was developed for silicon MOS transistors from liquid helium to room temperatures [17], as well as a method for parameter extraction which was oriented for very low temperatures [18].

Since the SOI technology became very attractive for highperformance and low-power applications (low leakage current, latch-up elimination, high soft error immunity, smaller subthreshold swing, reduced parasitic capacitance, simple device structure and process, etc.), similar low temperature research and deep analyses started on SOI MOSFETs, when focusing on the operation mode $[19,20]$, threshold voltage $[21,22]$, accentuated self-heating phenomenon [23], and parameters' extraction $[24,25]$.

The low temperature properties of SOI transistors are rather different from those of bulk devices as a consequence of the specific mechanisms existing in SOl structures. The 
device is partially depleted (PD) in the high temperature range and becomes fully depleted (FD) in the low temperature range. The reduction of the $V_{T}$ slope at low temperature occurs when the full depletion of the silicon film prevents the further extension of the depletion region under the gate [21]. Therefore, a substantial reduction of the variation of $V_{T}$ versus temperature can be achieved in a fully depleted SOl MOSFET because of the suppression of the variation of the depletion charge with the temperature.

In this paper, we present the influence and behavior of series resistance at low temperature for FD-SOI MOSFETs by comparing between ultrathin body (UTB) and gate recessed channel (GRC) devices. The parameter extraction is performed above the threshold voltage using $Y$-function method. This aims to explain the anomalous transport behavior of the GRC device between room temperature and $77 \mathrm{~K}$. This study comes to complete our previous works where we first evidenced the gate dependence of the series resistance $\left(R_{\mathrm{SD}}\right)$ in this device, using classic $I-V$ modeling [26] and $R_{m}-L$ and $C-V$ techniques [27-29], and used the $Y$-function method for parameters' extraction [30] for room temperature results.

\section{Device Processing and TCAD Simulation}

The layers deposition process was simulated by a commercial 3D TCAD process simulator (Csuprem) from Crosslight Software Inc. [31] according to the real process conditions we used to fabricate our devices as previously published [32]. The simulated 3D structure of the ultrathin body (UTB) device having a $46 \mathrm{~nm}$ thick body and channel and $W / L$ ratio of $10(80 \mu \mathrm{m} / 8 \mu \mathrm{m})$ and used as a reference device is presented in Figure 1(a). In Figure 1(b), we show the simulated 3D structure of $4.6 \mathrm{~nm}$ thick channel obtained by the gate recessed process, that is, the gate recessed channel (GRC) device having the same $W$ and $L$ values. As presented in the upper insert the active region (source, gate, and drain terminals) is terminated by aluminum contacts (layer 10) in the vertical axis and limited by field oxide (layer 07) borders in the horizontal axis. The buried oxide (layer 02) is serving as a barrier between the bulk silicon (layer 01) and the gate recessed silicon channel (layer 03).

The lower insert of Figure 1(b) represents a zoom-in of the gate recessed channel, when the silicon layer was thinned from $46 \mathrm{~nm}$ to $4.6 \mathrm{~nm}$. This points out advantage of the recessed process in which only the silicon channel is thinned while the source and drain regions and their respective extensions remain in their original (body) thickness. In addition to Figure 1, a complementary list of the process parameters at which most of them are used in the simulator was presented in summarizing Table 1. Both GRC and UTB devices were modeled in TCAD by applying almost the same process parameters used in their physical fabrications.

\section{Electrical Characterizations and Analysis}

3.1. Experiment Setup and Conditions. Using the Semiconductor Characterization System (SCS-4200) from Keithley

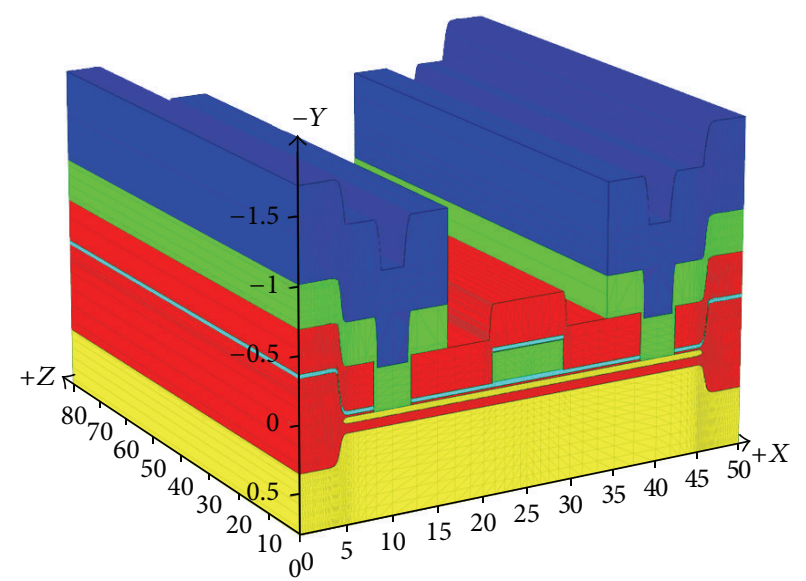

(a)

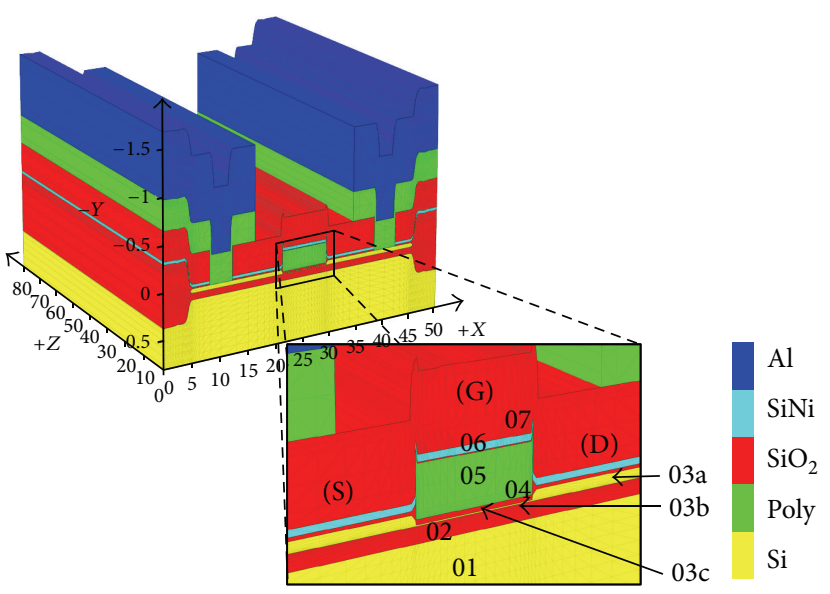

07. Field oxide

06. Nitride

05. Polysilicon

04. Gate oxide (GOX)

03a. Original silicon on insulator

03b. Gate recessed silicon channel 03c. Pad oxide (PAD OX)

02. Buried oxide (BOX)

01. Bulk silicon

(G) = gate

(D) $=$ drain

(S) = source (b)

FIgure 1: Cross view of a 3D TCAD (Csuprem) process simulation of UTB (a) and GRC (b) devices having a channel thickness of $46 \mathrm{~nm}$ and $4.6 \mathrm{~nm}$, respectively. The function and the process parameters of the numbered layers are given in Table 1.

Ltd., the $I-V$ measurements were first performed at room temperature ( $T=300 \mathrm{~K}$, dark conditions) in order to confirm the functionality of the measured transistors. The devices were inserted from the beginning on a cold finger support inside a Dewar specially designed for the experiments. Both $I_{\mathrm{DS}}-V_{\mathrm{DS}}$ and $I_{\mathrm{DS}}-V_{\mathrm{GS}}\left(g_{m}\right.$ slope $)$ characteristics were measured for each device, starting with the MOS standard $I_{\mathrm{DS}}-V_{\mathrm{GS}}$ curves to check standard functionality. After the functionality screening step passed, the temperature was slowly taken down to $77 \mathrm{~K}$. Stabilization time was required to assure the correct reading of the temperature in the vacuum chamber which was set to $2 \times 10^{-7}$ bar. Since the analysis focused on the 
TABLE 1: Process parameters for deposited layers of fabricated devices.

\begin{tabular}{|c|c|c|c|c|}
\hline Layer number & Layer name & Layer acronym & Layer thickness (nm) & Function and properties \\
\hline 01 & Bulk silicon & Bulk & 500,000 & $\begin{array}{l}\text { Substrate p-type boron }\left(10^{15} \mathrm{~cm}^{-3}\right) \\
\text { Resistivity: } 14-22 \Omega \cdot \mathrm{cm} \\
\text { orientation }<100>\end{array}$ \\
\hline 02 & Buried oxide & BOX & 70 & $\begin{array}{l}\text { Bulk insulator } \\
\left.\mathrm{O}^{+} \text {implantation energy: } 120 \mathrm{keV} \text { ( } 2.35 \text { hours }\right) \\
\text { Dose: } 0.3910^{18} \mathrm{O}^{+} \mathrm{cm}^{-2} \\
\text { Annealing: } 1320^{\circ} \mathrm{C}(6.00 \text { hours })\end{array}$ \\
\hline $03 \mathrm{a}$ & Silicon on insulator & SOI & 46 & $\begin{array}{l}\text { p-type boron }\left(10^{15} \mathrm{~cm}^{-3}\right) \text { regular transistor channel in UTB } \\
\text { devices and nonreduced SOI in GRC devices (source/drain } \\
\text { extensions) }\end{array}$ \\
\hline $03 \mathrm{~b}$ & Gate recessed silicon & GRS & 1.6-6.5 range & Thinned transistor channel in GRC devices \\
\hline $03 \mathrm{c}$ & Pad oxide & PAD OX & 15 & Relieve stress from silicon to nitride at high temperature \\
\hline 04 & Gate oxide & GOX & 26 & Gate insulator \\
\hline 05 & Polysilicon & Poly & 220 & Gate electrode \\
\hline 06 & Nitride 2 & Nit & 30 & $\begin{array}{l}\text { Prevent further oxidation of the thin silicon layer during the } \\
\text { implant's thermal annealing (GRC) }\end{array}$ \\
\hline 07 & Field oxide & FOX & 700 & Active area insulator \\
\hline 08 & Silox & SOX & 350 & Contact opening mask for source/drain and gate passivation \\
\hline 09 & Polysilicon & Poly & 220 & $\begin{array}{l}\text { Source/drain Polycontacts } \\
\text { Source/drain doping obtained by phosphorous implant: } \\
\text { dose } D=2.510^{15} \mathrm{~cm}^{-2} \text {, } \\
\text { energy } E=30 \mathrm{keV} \text {, and } \\
\text { HTA high temperature annealing } T=1000^{\circ} \mathrm{C}(30 \mathrm{~min})\end{array}$ \\
\hline 10 & Aluminum & $\mathrm{Al}$ & 500 & Source/drain metal contacts \\
\hline
\end{tabular}

gate voltage range, above the threshold voltage, and on the $Y$ function parameters extraction method, the respective linear transfer characteristics were deeply studied and compared in this paper.

3.2. Threshold Voltage and Mobility Extraction Using YFunction. The $I_{\mathrm{DS}}$ versus $V_{\mathrm{GS}}$ transfer characteristics (ranging from 0 to $+7 \mathrm{~V}$ ) were measured in the linear domain, that is, for two low values of drain voltage $\left(V_{\mathrm{DS}}\right): 0.05 \mathrm{~V}$ and $0.1 \mathrm{~V}$ and above their respective threshold voltage $V_{T}$. In Figures 2(a) and 2(b), these characteristics are presented at linear scale for the UTB device ( $46 \mathrm{~nm}$ channel thick) at $300 \mathrm{~K}$ (room temperature) and at $77 \mathrm{~K}$ (liquid nitrogen), respectively. In Figures 2(c) and 2(d), the corresponding characteristics are presented for the GRC device $(2.2 \mathrm{~nm}$ channel thick) at $300 \mathrm{~K}$ and $77 \mathrm{~K}$, respectively. As observed in Figures 2(a) and 2(c), the GRC's drain current measured at $300 \mathrm{~K}$ (for $\left.V_{\mathrm{GS}}=7 \mathrm{~V}\right)$ is three orders of magnitude lower than those measured for UTB's at the same temperature. But at $77 \mathrm{~K}$, as shown in Figures 2(b) and 2(d), this current ratio has almost reached five orders of magnitude. Such a huge current attenuation is not necessarily connected to a dumping of the electron mobility but can be related to the apparition of a huge series resistance during the channel thinning (gate recessed process). In order to discriminate the influence of the series resistance on the extraction of intrinsic device parameters, like threshold voltage and electron mobility, it is a common practice to use an extraction method based on the $Y$-function analysis. It is important to pay attention that
Figures 2(d) and 3(d) (resp., $I_{\mathrm{DS}}-V_{\mathrm{GS}}$ characteristics and $Y$ Function graphs) are presenting some fluctuation steps in their respective curves for GRC devices at $T=77 \mathrm{~K}$.

The $Y$-method first introduced by Ghibaudo [1] has the interest to separate the respective contributions of the intrinsic channel conduction from the series resistance effect. However, this technique usually needs a set of devices with different channel lengths. As a novelty, we proposed, in a previous work [30], applying this method to our devices having a single channel length value by varying the drain voltage $V_{\mathrm{DS}}$ in the whole linear mode. In this case, we should take into account the $V_{\mathrm{DS}} / 2$ contribution in the potential of inversion layer $\left(V_{\mathrm{GS}}-V_{T}\right)$. Accordingly, the $Y$-function is expressed as follows:

$$
Y \equiv \frac{I_{\mathrm{DS}, \text { lin }}}{\sqrt{g_{m}}}=\sqrt{\beta V_{\mathrm{DS}}}\left(V_{\mathrm{GS}}-V_{T}-\frac{V_{\mathrm{DS}}}{2}\right)=a_{Y}+b_{Y} V_{\mathrm{GS}} .
$$

Assume

$$
I_{\mathrm{DS}, \text { lin }} \equiv \beta \frac{\left(V_{\mathrm{GS}}-V_{T}-V_{\mathrm{DS}} / 2\right)}{1+\theta_{1,0}\left(V_{\mathrm{GS}}-V_{T}\right)} V_{\mathrm{DS}}
$$

where

$$
\beta=\frac{W}{L} C_{\mathrm{ox}} \mu_{0}
$$




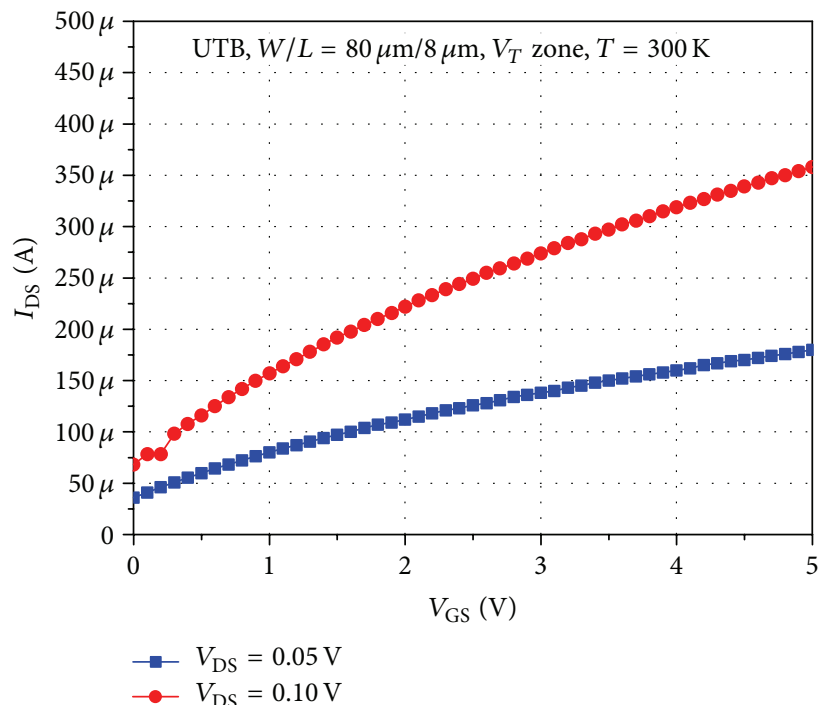

(a)

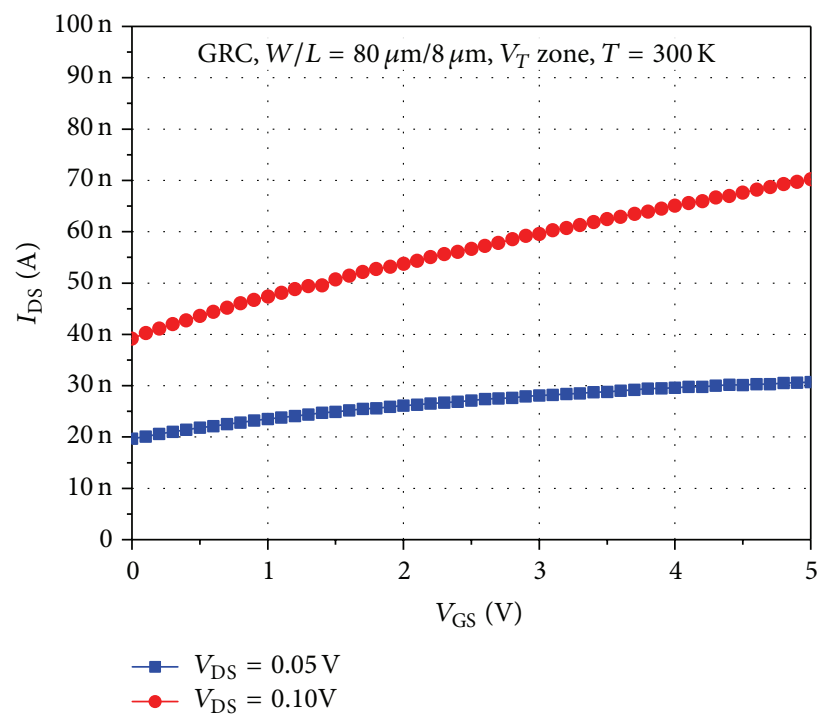

(c)

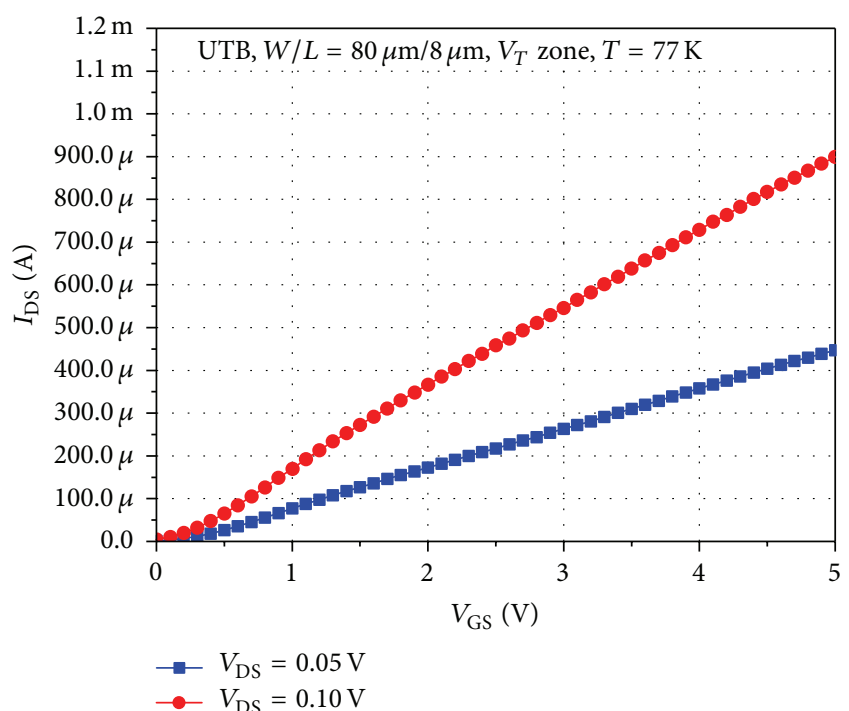

(b)

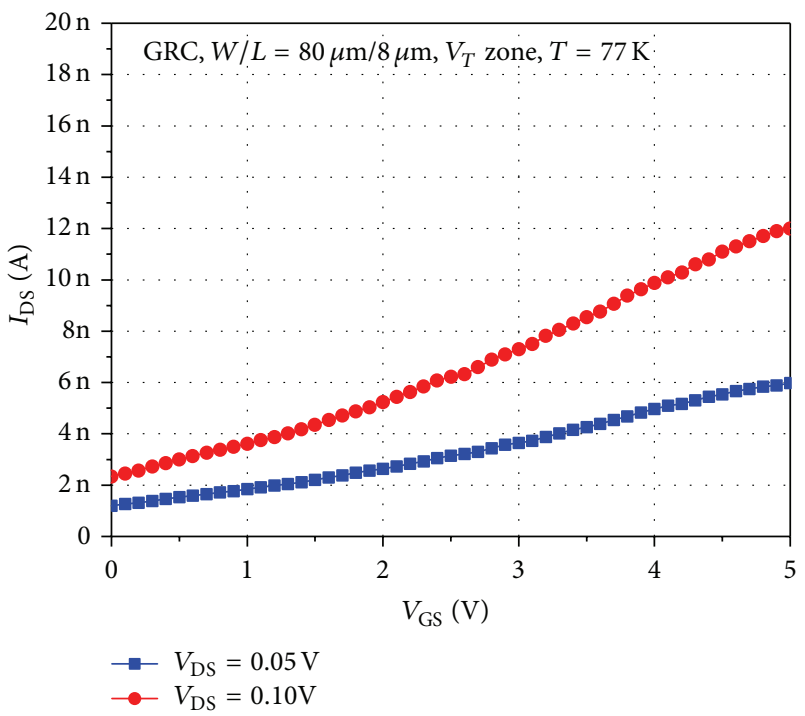

(d)

FIGURE 2: $I_{\mathrm{DS}}-V_{\mathrm{GS}}$ characteristics measured above the threshold domain (linear domain) for UTB $\left(t_{\mathrm{Si}}=46 \mathrm{~nm}\right)$ and GRC $\left(t_{\mathrm{Si}}=2.2 \mathrm{~nm}\right)$, for two low $V_{\mathrm{DS}}$ values $(0.05 \mathrm{~V}$ and $0.1 \mathrm{~V}$ ): (a): UTB, $W / L=80 \mu \mathrm{m} / 8 \mu \mathrm{m}$ and $T=300 \mathrm{~K}$. (b): UTB, $W / L=80 \mu \mathrm{m} / 8 \mu \mathrm{m}$ and $T=77 \mathrm{~K}$. (c): GRC, $W / L=80 \mu \mathrm{m} / 8 \mu \mathrm{m}$ and $T=300 \mathrm{~K}$. (d): GRC, $W / L=80 \mu \mathrm{m} / 8 \mu \mathrm{m}$ and $T=77 \mathrm{~K}$.

And $\mu_{0}$ is the low field electron mobility, while $\theta_{1,0}$ is the "intrinsic" mobility degradation factor. By using the effective mobility, $\mu_{\mathrm{eff}}$ is given by the empirical relationship

$$
\mu_{\mathrm{eff}} \equiv \frac{\mu_{0}}{1+\theta_{1,0}\left(V_{\mathrm{GS}}-V_{T}\right)} .
$$

Here we do not need to take into account the second degree degradation factor, unlike $[5,8]$, since the oxide equivalent thickness of our devices is large enough to avoid such term.

The $Y-V_{\mathrm{GS}}$ graphs can be straightforward derived from the $I_{\mathrm{DS}}-V_{\mathrm{GS}}$ characteristics, as shown in Figures 3(a) and 3(b) for UTB at $300 \mathrm{~K}$ and $77 \mathrm{~K}$, respectively. In Figures 3(c) and $3(\mathrm{~d}), Y-V_{\mathrm{GS}}$ are presented for GRC at $300 \mathrm{~K}$ and $77 \mathrm{~K}$, respectively. We can see there that, for positive $V_{\mathrm{GS}}$ values, the
$Y$-functions are almost linear for UTBs but are significantly bended at higher $V_{\mathrm{GS}}$ values for GRC at $77 \mathrm{~K}$. Moreover the slopes are $V_{\mathrm{DS}}$ dependent for UTB but almost independent for GRC.

Since the slope is not a pure constant of $V_{\mathrm{GS}}$, in particular for GRC's devices, we will consider the maximum value of the $Y$-slope $\left(Y_{\max }^{\prime}\right)$ as the $b_{Y}$ parameter [30]. So, we can extract the threshold value $V_{T}$ from the intercept of the tangent of the $Y$ function with the $V_{\mathrm{GS}}$ axis, according to the following:

$$
\begin{aligned}
V_{T} & \equiv V_{T, Y_{\max }^{\prime}} \\
& =V_{\mathrm{GS}}\left(b_{Y}\right)-\frac{Y_{\max }}{Y_{\max }^{\prime}}-\frac{V_{\mathrm{DS}}}{2} \quad \text { with } Y_{\max } \equiv Y\left[V_{\mathrm{GS}}\left(b_{Y}\right)\right] .
\end{aligned}
$$




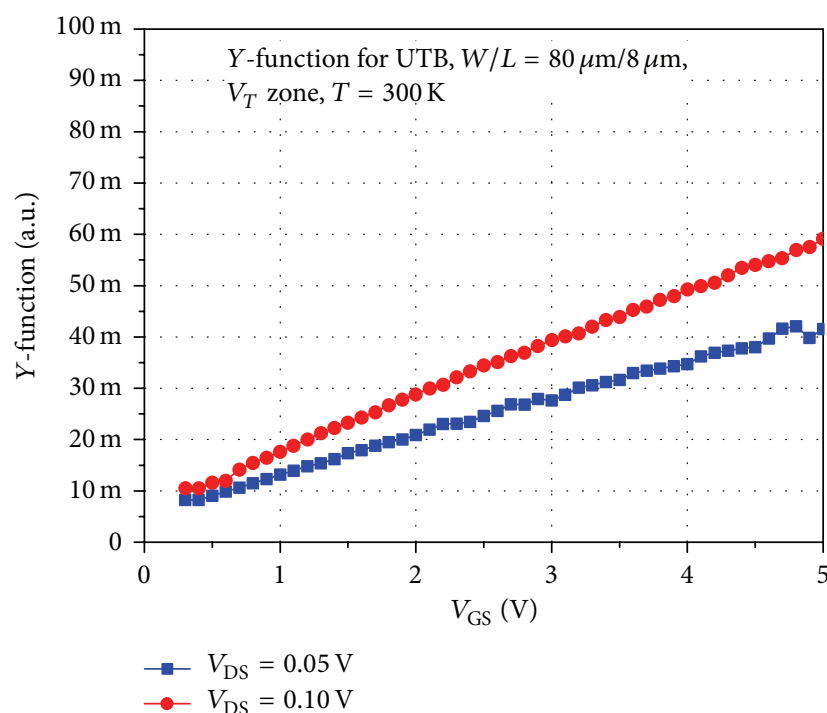

(a)

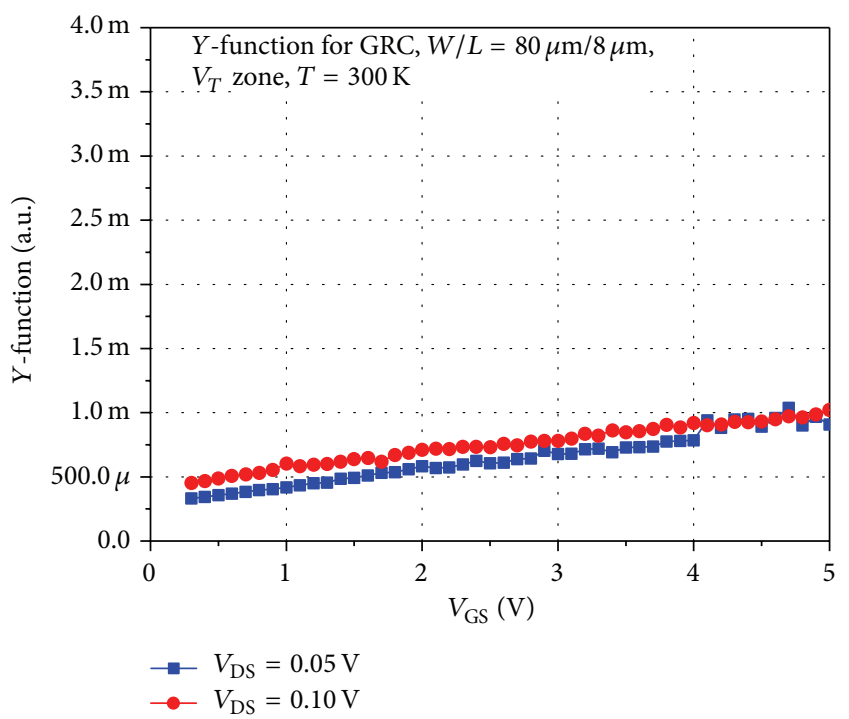

(c)

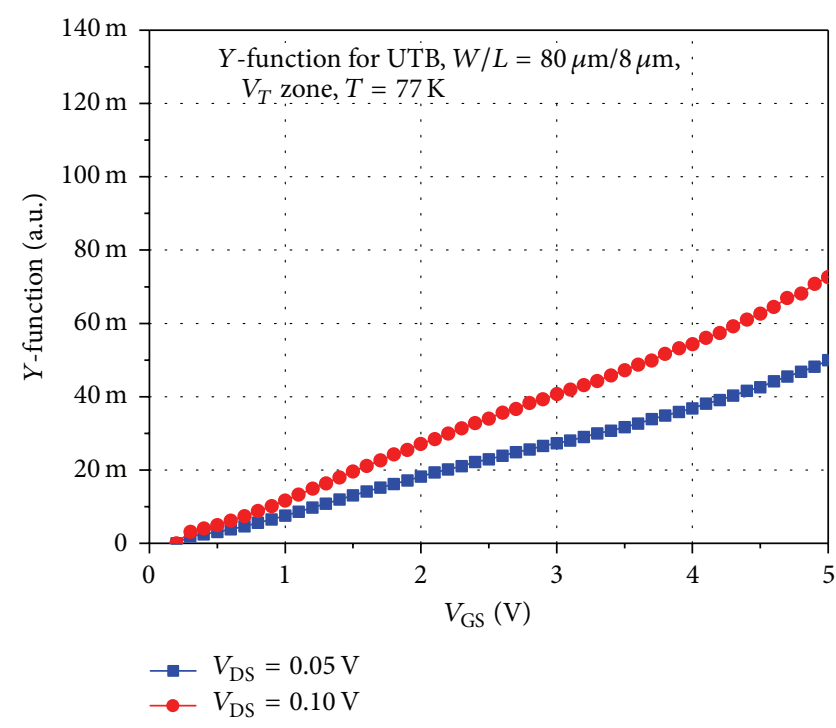

(b)

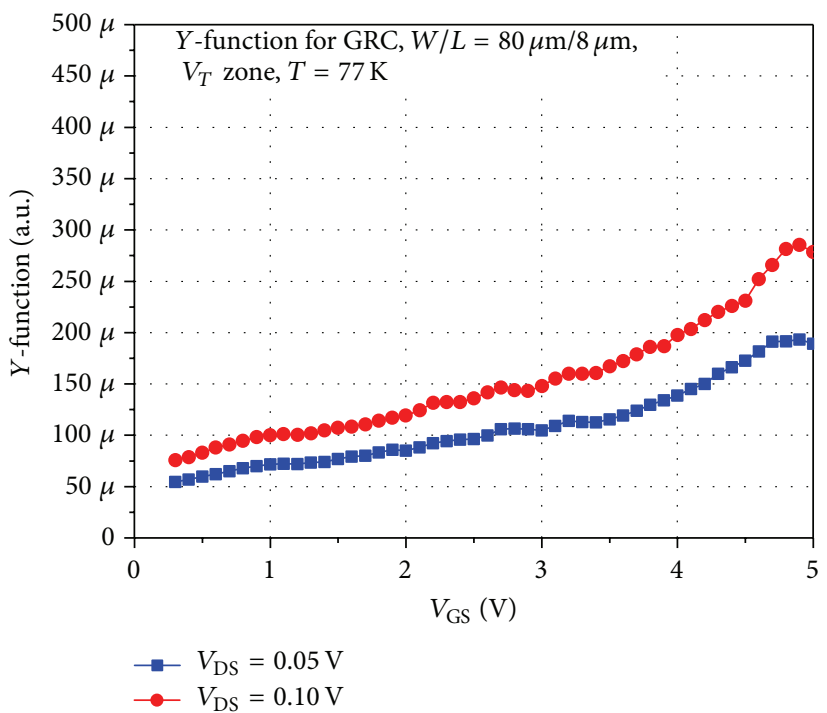

(d)

FIGURE 3: $Y$-functions measured above the threshold domain (linear domain) for UTB $\left(t_{\mathrm{Si}}=46 \mathrm{~nm}\right)$ and GRC $\left(t_{\mathrm{Si}}=2.2 \mathrm{~nm}\right)$, for two low $V_{\mathrm{DS}}$ values $(0.05 \mathrm{~V}$ and $0.1 \mathrm{~V}$ ): (a): UTB, $W / L=80 \mu \mathrm{m} / 8 \mu \mathrm{m}$ and $T=300 \mathrm{~K}$. (b): UTB, $W / L=80 \mu \mathrm{m} / 8 \mu \mathrm{m}$ and $T=77 \mathrm{~K}$. (c): GRC, $W / L=$ $80 \mu \mathrm{m} / 8 \mu \mathrm{m}$ and $T=300 \mathrm{~K}$. (d): GRC, $W / L=80 \mu \mathrm{m} / 8 \mu \mathrm{m}$ and $T=77 \mathrm{~K}$.

The low field electron mobility can be also extracted from the slope parameter $\left(b_{Y}\right)$ of the $Y$-function using the following equations:

$$
\mu_{0}=\beta\left(\frac{L}{W C_{\mathrm{ox}}}\right)
$$

where

$$
\beta=\frac{b_{Y}^{2}}{V_{\mathrm{DS}}} .
$$

For GRC type devices, the front gate capacitance $\left(C_{\mathrm{ox}}\right)$ value was $138 \mathrm{nF} / \mathrm{cm}^{2}$, for a $26 \mathrm{~nm}$ front gate oxide (GOX) thickness. For UTB the $C_{\mathrm{ox}}$ value was slightly lower $\left(121 \mathrm{nF} / \mathrm{cm}^{2}\right)$ due to the $38 \mathrm{~nm}$ thick nitride layer capping the pad oxide in the gate region.

The extracted values of $V_{T}$ and $\mu_{0}$ obtained at $V_{\mathrm{DS}}=0.05 \mathrm{~V}$ and $V_{\mathrm{DS}}=0.1 \mathrm{~V}$ conditions are averaged and summarized in Table 2.

Note that both UTB and GRC are depletion-mode devices at $300 \mathrm{~K}$ (negative $V_{T}$ for p-type channel). From Table 2, we can see that the UTB's threshold voltage and the low field electron mobility are strongly increased by decreasing the temperature from $300 \mathrm{~K}$ to $77 \mathrm{~K}$. Conversely, for GRC's, the threshold voltage and the low field electron mobility are both 
TABLE 2: Summarizing table of the threshold voltage $V_{T}$, the $\beta$ factor, and the low field mobility extracted from the $Y$-function intersections and slopes and for UTB and GRC devices at $300 \mathrm{~K}$ and $77 \mathrm{~K}$. A third row of UTB/GRC indicative ratios was added to emphasize the parameters difference between the two devices, built in the same conditions and process.

\begin{tabular}{lcccccc}
\hline & \multicolumn{3}{c}{$T=300 \mathrm{~K}$} & \multicolumn{2}{c}{$T=77 \mathrm{~K}$} \\
& $V_{T}(\mathrm{~V})$ & $\beta(\mu \mathrm{S} / \mathrm{V})$ & $\mu_{0}\left(\mathrm{~cm}^{2} / \mathrm{Vs}\right)$ & $V_{T}(\mathrm{~V})$ & $\beta(\mu \mathrm{S} / \mathrm{V})$ & $\mu_{0}\left(\mathrm{~cm}^{2} / \mathrm{Vs}\right)$ \\
\hline $\mathrm{UTB}\left(t_{\mathrm{Si}}=46 \mathrm{~nm}\right)$ & -0.65 & 1470 & 1210 & +0.26 & 2410 & 2000 \\
$\mathrm{GRC}\left(t_{\mathrm{Si}}=2.2 \mathrm{~nm}\right)$ & -2.35 & 31 & 0.222 & -2.60 & 0.007 & 0.005 \\
Parameter ratio UTB/GRC & 0.28 & 47.42 & 5,450 & -0.10 & 344,286 & 400,000 \\
\hline
\end{tabular}

TABLE 3: Summarizing table of $R_{\mathrm{SD}}$ and $\theta_{1,0}$ values extracted from the $\theta_{1}$ versus $\beta$ relationship. A third row of, this time, GRC/UTB indicative ratios was added to emphasize the parameters difference between the two devices and the huge $R_{\mathrm{SD}}$ ratio differences, built in the same conditions and process.

\begin{tabular}{|c|c|c|c|c|c|c|}
\hline & \multicolumn{3}{|c|}{$T=300 \mathrm{~K}$} & \multicolumn{3}{|c|}{$T=77 \mathrm{~K}$} \\
\hline & $R_{\mathrm{SD}}(\mathrm{k} \Omega)$ & $\theta_{1,0}\left(\mathrm{~V}^{-1}\right)$ & $R_{\mathrm{SD}} \beta\left(\mathrm{V}^{-1}\right)$ & $R_{\mathrm{SD}}(\mathrm{k} \Omega)$ & $\theta_{1,0}\left(\mathrm{~V}^{-1}\right)$ & $R_{\mathrm{SD}} \beta\left(\mathrm{V}^{-1}\right)$ \\
\hline $\operatorname{UTB}\left(t_{\mathrm{si}}=46 \mathrm{~nm}\right)$ & 0.103 & 0.0215 & 0.151 & 0.046 & -0.019 & 0.11 \\
\hline $\operatorname{GRC}\left(t_{\mathrm{si}}=2.2 \mathrm{~nm}\right)$ & 1730 & -0.176 & 0.530 & 8930 & -0.146 & 0.06 \\
\hline Parameter ratio GRC/UTB & 16,796 & -8.19 & 3.51 & 194,130 & 7.68 & 0.54 \\
\hline
\end{tabular}

decreased accordingly by decreasing the temperature from $300 \mathrm{~K}$ to $77 \mathrm{~K}$.

If, for UTBS, the extracted $\mu_{0}$ values are similar to those expected in silicon based devices, for GRC device, the corresponding $\mu_{0}$ values are found very low and are inconsistent with the measured values of such kind of fully depleted SOI MOSFET's [33].

3.3. Series Resistance Extraction from $\theta_{1}$ versus $\beta$ Using $X$ Function for Variable $V_{D S}$. By introducing the series resistance $R_{\mathrm{SD}}$ in (2) and assuming $R_{\mathrm{S}}=R_{\mathrm{D}}=R_{\mathrm{SD}} / 2$, we get the classic expression

$$
I_{\mathrm{DS}, \text { lin }}=\beta \frac{\left(V_{\mathrm{GS}}-V_{T}-V_{\mathrm{DS}} / 2\right)}{1+\theta_{1}\left(V_{\mathrm{GS}}-V_{T}\right)} V_{\mathrm{DS}},
$$

where $\theta_{1}$ is the "extrinsic" mobility degradation factor including the series resistance according to

$$
\theta_{1}=\theta_{1,0}+R_{\mathrm{SD}} \beta
$$

The mobility degradation factor $\theta_{1}$ can be calculated using the $X$-function defined in [5]

$$
X \equiv \frac{1}{\sqrt{g_{m}}}=\frac{1+\theta_{1}\left(V_{\mathrm{GS}}-V_{T}\right)}{\sqrt{\beta V_{\mathrm{DS}}}}=a_{X}+b_{X} V_{\mathrm{GS}} .
$$

Like $Y$-function, $X$ is not a pure linear function of $V_{\mathrm{GS}}$ especially for GRC's devices. Consequently, we consider $b_{X}$ as the maximum value of the $X$-function slope $\left(X_{\max }^{\prime}\right)$. So, according to (10), the $\theta_{1}$ values can be extracted as follows:

$$
\theta_{1}=b_{X} \sqrt{\beta V_{\mathrm{DS}}}=b_{X} \cdot b_{Y} .
$$

Since $\beta$ is $V_{\mathrm{DS}}$ dependent, as seen from the previous $Y$ function analysis, we can plot $\theta_{1}$ versus $\beta$ according to (9) for the different $V_{\mathrm{DS}}$ values. In our case, $R_{\mathrm{SD}}$ is simply the slope of this plot, while $\theta_{1,0}$ is the intersection of the linear fit with the vertical $\left(\theta_{1}\right)$ axis. In case of fluctuations in the $X^{\prime}-V_{\mathrm{GS}}$ graph, as observed for GRC's, the $X_{\max }^{\prime}$ point is optimally chosen in order to get a coherent positive value of $R_{\mathrm{SD}}$. The extracted values are summarized in Table 3.

It turns out that for the UTB device, the series resistance $R_{\mathrm{SD}}$ is decreased by a factor of 2 when decreasing the temperature from $300 \mathrm{~K}$ to $77 \mathrm{~K}$ while for GRC, $R_{\mathrm{SD}}$ is increased by a factor of 5 . Moreover, the $\theta_{1,0}$ is found negative for UTB at $77 \mathrm{~K}$ and for GRC at both temperatures.

From the above equations, it is also possible to extract the analytical expression of $R_{\mathrm{SD}}$ as function of $V_{\mathrm{GS}}$ using the $X Y$ product as follows:

$$
\begin{aligned}
R_{\mathrm{SD}}= & \frac{V_{\mathrm{DS}}}{Y^{2}}\left(V_{\mathrm{GS}}-V_{T}-\frac{V_{\mathrm{DS}}}{2}\right)^{2} \\
& \times\left[\left(\frac{X Y}{V_{\mathrm{GS}}-V_{T}-\left(V_{\mathrm{DS}} / 2\right)}-1\right) \frac{1}{V_{\mathrm{GS}}-V_{T}}-\theta_{1,0}\right] .
\end{aligned}
$$

The calculated $R_{\mathrm{SD}}$ values modeled by (12) using the $\theta_{1,0}$ parameters values from Table 3 are shown in Figure 4 for UTB and GRC devices at $300 \mathrm{~K}$ and $77 \mathrm{~K}$.

As a first observation, it appears from Figures 4(a) to 4(d) that small $V_{\mathrm{DS}}$ values $(0.05 \mathrm{~V}$ and $0.1 \mathrm{~V})$ are not influencing the series resistance behavior, since the curves remain almost matched at both $300 \mathrm{~K}$ and $77 \mathrm{~K}$ temperatures.

For UTB device, the $R_{\mathrm{SD}}$ series resistance is decreasing by a factor 5 by lowering temperature at moderate gate voltage overdrive (e.g., $R_{\mathrm{SD}}=100 \Omega$ at $T=300 \mathrm{~K}$ versus $R_{\mathrm{SD}}=10 \Omega$ at $T=77 \mathrm{~K}$, for $\left.V_{\mathrm{GS}}-V_{T}=3 \mathrm{~V}\right)$. The opposite phenomenon is observed for GRC device $\left(R_{\mathrm{SD}}=1.75 \mathrm{M} \Omega\right.$ at $T=300 \mathrm{~K}$ versus $R_{\mathrm{SD}}=10 \mathrm{M} \Omega$ at $T=77 \mathrm{~K}$, for $V_{\mathrm{GS}}-V_{T}=3 \mathrm{~V}$ ). In all cases, the $R_{\mathrm{SD}}$ series resistance is found decreasing for moderated values of $V_{\mathrm{GS}}-V_{T}(<4 \mathrm{~V})$ while for higher $V_{\mathrm{GS}}-V_{T}$ values, $R_{\mathrm{SD}}$ is found increasing. 


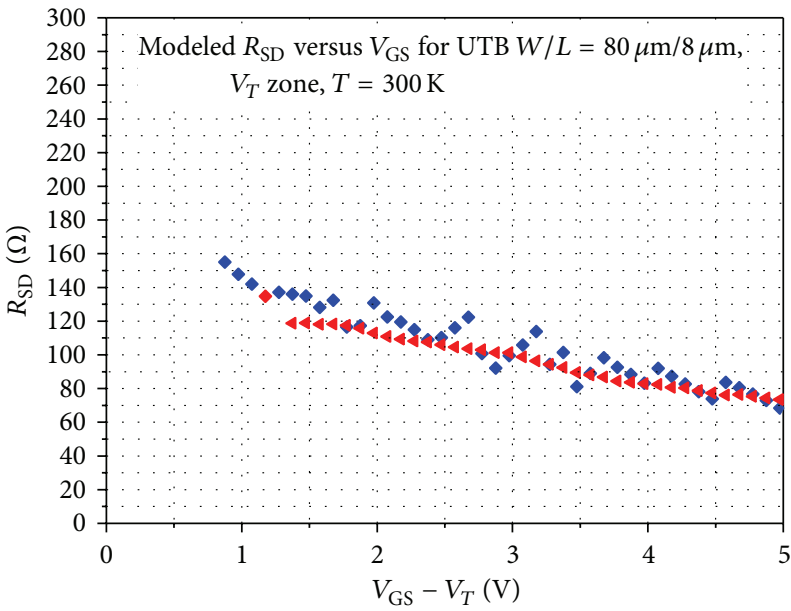

$4 V_{\mathrm{DS}}=0.10 \mathrm{~V}$

- $V_{\mathrm{DS}}=0.05 \mathrm{~V}$

(a)

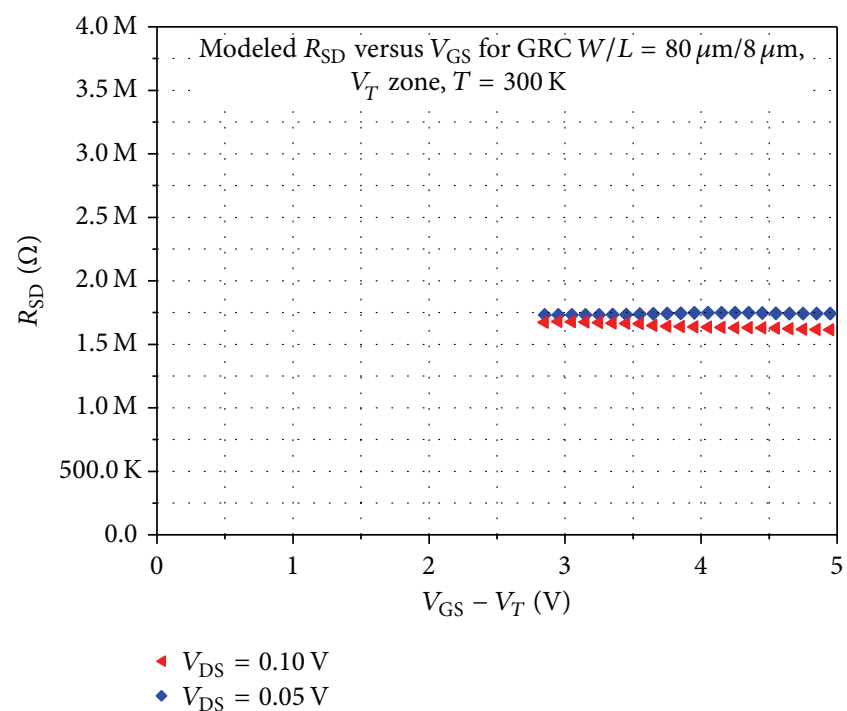

(c)

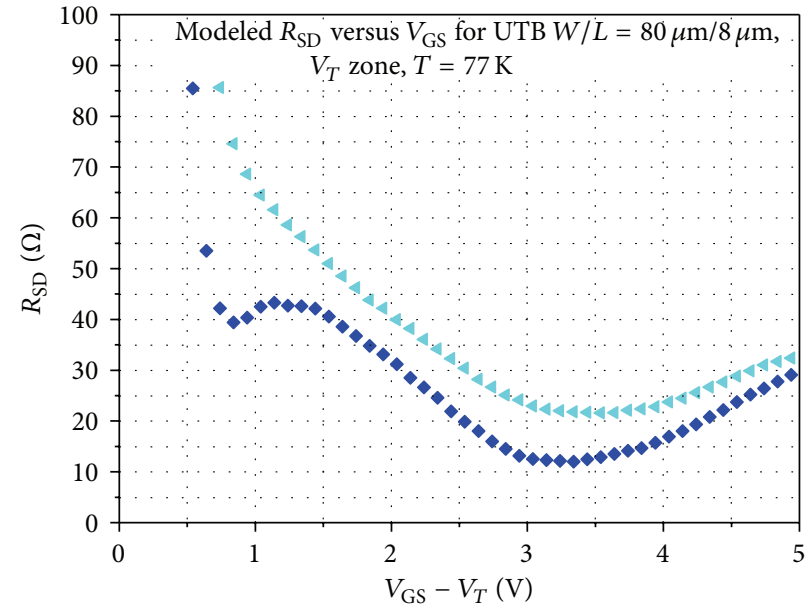

$\triangleleft V_{\mathrm{DS}}=0.10 \mathrm{~V}$

- $V_{\mathrm{DS}}=0.05 \mathrm{~V}$

(b)

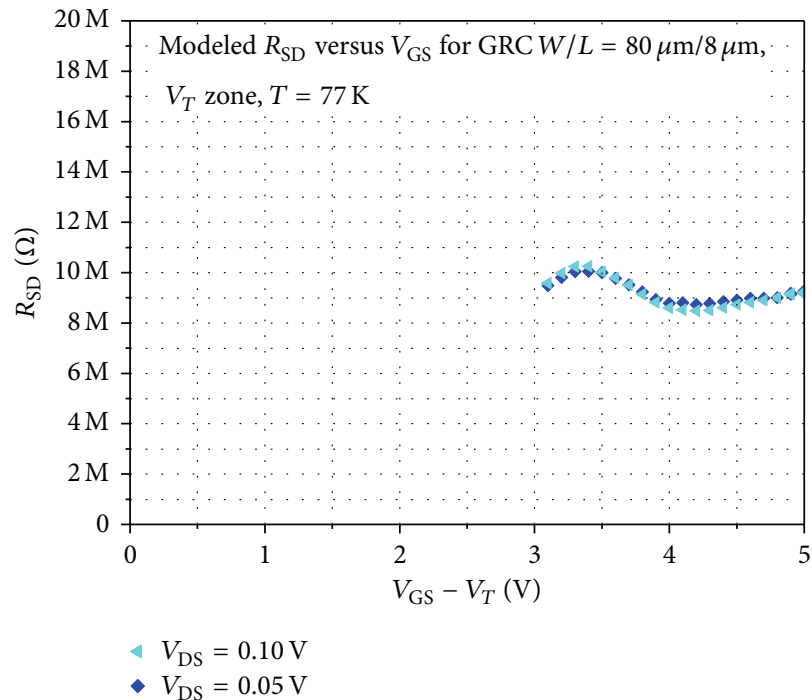

(d)

FIGURE 4: Modeled $R_{\mathrm{SD}}$ versus the gate voltage overdrive $\left(V_{\mathrm{GS}}-V_{T}\right)$, as extracted from the $Y$-function for $\mathrm{UTB}\left(t_{\mathrm{Si}}=46 \mathrm{~nm}\right)$ and for GRC $\left(t_{\mathrm{Si}}\right.$ $=2.2 \mathrm{~nm}$ ): (a): UTB, $W / L=80 \mu \mathrm{m} / 8 \mu \mathrm{m}$ and $T=300 \mathrm{~K}$. (b): UTB, $W / L=80 \mu \mathrm{m} / 8 \mu \mathrm{m}$ and $T=77 \mathrm{~K}$. (c): GRC, $W / L=80 \mu \mathrm{m} / 8 \mu \mathrm{m}$ and $T=$ $300 \mathrm{~K}$. (d): GRC, $W / L=80 \mu \mathrm{m} / 8 \mu \mathrm{m}$ and $T=77 \mathrm{~K}$.

\section{Interpretation and Discussion}

4.1. Behavior of the Threshold Voltage at Low Temperature. According to Table 2, for UTB device the negative slope of $V_{T}$ with temperature $\left(\Delta V_{T} / \Delta T=-2.7 \mathrm{mV} / \mathrm{K}\right)$ can be related to the linear decrease of the Fermi potential with temperature as already observed in fully depleted (FD) and partially depleted (PD) SOI MOSFET [34]. However, for GRC, the threshold voltage is almost insensitive to temperature which is unexpected. In [34], the $\Delta V_{T} / \Delta T$ slope of FD was found lower than the PD on the channel thickness, meaning that for thinner channel the $V_{T}$ is less sensitive to temperature as seen for our GRC device.
Previous works on ultrathin FD-SOI MOSFET devices at low temperatures have raised the explanation of the electrical behavior by quantum effects $[33,35]$. For example, it was reported that for channel thickness of $t_{\mathrm{Si}}=30 \mathrm{~nm}$ when the operating temperature was decreased from room to low temperatures, the threshold voltage $V_{T}$ and the subthreshold slope increased. It was clearly reported that fluctuations of the drain current and the transconductance were due to quantum-mechanical phenomena found at operating temperature of $77 \mathrm{~K}$ [36]. Moreover, the threshold voltage increases steadily in SOI films thinner than $t_{\mathrm{Si}}=6 \mathrm{~nm}$, due to the occurrence of quantum effects. As mentioned above, in our case, the device channel thickness is $t_{\mathrm{Si}}=2.2 \mathrm{~nm}$, so 
we can assume, as a first approach, such kind of mechanisms may be responsible for the observed $V_{T}$ variations.

The fluctuation steps, observed in $I_{\mathrm{DS}}-V_{\mathrm{GS}}$ characteristics (Figure $2(\mathrm{~d})$ ), are accentuated in $Y$-function curves (Figure 3(d)) since they are obtained from the derivative of the former characteristics. Such step phenomena were already reported as quantum effects for channel having $t_{\mathrm{Si}}$ $=30 \mathrm{~nm}$ [36]. The fluctuations of the $I_{\mathrm{DS}}-V_{\mathrm{GS}}$ characteristics indicating some oscillations of $I_{\mathrm{DS}}$ and $Y$ in the subthreshold current region are believed to correspond to a Coulomb blockade [19], because of the combination of a large undulation period, and the local roughness will result in coupled barriers inside a channel.

4.2. Behavior of the Low Field Mobility at Low Temperature. According to Table 1, we noticed that, for UTB's, the electron low field mobility $\mu_{0}$ is close to the bulk silicon value at $300 \mathrm{~K}$ $\left(1300 \mathrm{~cm}^{2} / \mathrm{Vs}\right)$ but much lower than the bulk value at $77 \mathrm{~K}$ $\left(7560 \mathrm{~cm}^{2} / \mathrm{Vs}\right)$. The increase of $\mu_{0}$ is consistent with the classic behavior of the carrier mobility in this range of temperature due to the freezing of the lattice phonon scattering in silicon [37].

However, for GRC device, the electron low field mobility $\mu_{0}$ values are found abnormally low comparatively to published data in such devices for both temperatures $[5,8$, 33]. Moreover, unlike UTB's, $\mu_{0}$ is found decreasing when decreasing the temperature.

From Table 2, we see that the $\theta_{1,0}$ values are found surprisingly negative for UTB at $77 \mathrm{~K}$ but are still negligible relative to $R_{\mathrm{SD}} \beta$, for GRC at both $300 \mathrm{~K}$ and $77 \mathrm{~K}$. However, such surprising results have been observed in an early study about SOI MOSFET according to McLarty et al. [38]. One may argue that a second order dependence on $V_{\mathrm{GS}}$ may be responsible for the nonlinearity of the $Y$-function as mentioned in [38] and more recently by Cros et al. [5]. This approach was efficient for a very thin gate oxide $(<10 \mathrm{~nm})$ where interface scattering is a dominant issue such that the mobility is found to be more degraded at the top interface than at the bottom interface, indicating that defects are more numerous at the top channel region [39]. But in our case, due to the relative thick oxide layer of our devices $(25 \mathrm{~nm})$, the latter consideration is not relevant so we could limit our analysis to the first order dependence for moderate values of $V_{\mathrm{GS}}$. Another explanation was reported in [35], for which the processing of source and drain regions may also be at the origin of additional scattering centers near the source and drain regions. All these observations lead us to conclude that the electron mobility extraction using $Y$-function is not physically coherent for UTB at $77 \mathrm{~K}$ nor for GRC at both temperatures.

4.3. Behavior of the Series Resistance at Low Temperature. It is well known that the field effect mobility of long-channel MOSFETs $(10 \mu \mathrm{m})$ can be strongly affected by additional series resistance [16]. This is particularly important at low temperature for which the channel resistance is lowered by the enhancement of the mobility. Since $R_{\mathrm{SD}}$ and $L_{\text {eff }}$ are both critical parameters for device modeling, many studies were published in the past decades for both room and cryogenics temperatures [24].

The series resistance dependence on gate voltage was originally observed for LDD devices [40] but also for non-LDD devices [41]. Simultaneously, for short channel devices, the electrical effective channel length $\left(L_{\text {eff }}\right)$ is reduced, and found also gate voltage dependent. However for all our devices the channel is long enough $(8 \mu \mathrm{m})$, so the short channel effects are a priori negligible in our study. Nevertheless, since the $\beta$ parameter is found $V_{\mathrm{DS}}$ dependent, which is not expected from (6) for a long-channel device, it turns out that the device conduction may be in fact connected to a short channel effect.

From Table 3 and Figure 4, we observed an increase by a factor 2 of the UTB's series resistance $R_{\mathrm{SD}}$ when decreasing the temperature from $300 \mathrm{~K}$ to $77 \mathrm{~K}$. This trend has been also observed for bulk $n$-MOSFETs [24]. Indeed, below $150 \mathrm{~K}$, the freeze-out effect of the doping impurities leads to an increase of the parasitic series resistance as reported in [25]. This effect is particularly enhanced in LDD and depletion-mode devices [42].

The decrease of the low field mobility by lowering the temperature was recently reported in [36] for nano-CMOS devices having a sub-100 $\mathrm{nm}$ channel length. All these observations reinforce the interpretation that, for GRC's, the conduction may no longer be governed by the channel inversion but is screened by a huge series resistance depending on $V_{\mathrm{GS}}$ [26-30].

We may interpret the series resistance effect by considering the bottleneck regions at the edge of the GRC channel as parasitic short channel transistors that are controlled by a fringing field from the gate. Another reason for the increase of the series resistance may be increasing the dopant concentration in the drain/source extensions zones due to lateral diffusion from the source/drain occurring during the gate recessed process.

4.4. Limitations of Extraction Method at High $V_{G S}$. On one side, Emrani et al. reported a general $Y$-function as $Y=$ $\left(I_{\mathrm{DS}}^{2} / g_{m}\right)^{1 / n}$, where $n$ is an empirical coefficient depending on temperature. The reported values are $n=2$ in the range of $T=200-300 \mathrm{~K}$ and $n=3$ at $T=4.2 \mathrm{~K}$ (liquid helium) while $n=2.4$ is the best value at $80 \mathrm{~K}[15,17]$. On the other side, Simoen et al. [24] used a similar analysis and found $n=2.08$ for $77 \mathrm{~K}$ and $n=1.92$ for $T=300 \mathrm{~K}$ for MOS devices having a high resistive silicon substrate. The change of $n$ value is attributed to a change of the scattering process. Indeed, if phonon scattering dominates near room temperature, other mechanisms such as Coulomb scattering by interfaces charges and surface roughness scattering are dominant at low temperatures for low and high transverse field, respectively [33]. However, for highly resistive devices, the influence of the temperature on $n$ value is small which suggests that the scattering mechanism is still dominated by phonon scattering.

In our case, for GRC's devices, the first order analysis (corresponding to $n=2$ ) of the $Y$-function leads to a coherence discrepancy for the electron mobility and also for $R_{\mathrm{SD}}$ at high transverse field. However, at $300 \mathrm{~K}$, it allows 
discriminating the contribution of the mobility from the series resistance with a good degree of confidence. This leads to confirmation the predominant role of the gate voltage dependent series resistance at both temperatures.

\section{Conclusion}

$Y$-function method based on a first order analysis has been shown to be effective to interpret the radically opposite electrical behavior which was observed at low temperature between ultrathin body (UTB) and gate recessed channel (GRC) devices, sharing the same $W / L$ ratio but having a channel thickness $t_{\mathrm{Si}}$ of $46 \mathrm{~nm}$ and $2.2 \mathrm{~nm}$, respectively. When decreasing the temperature the apparent conductivity was increased in UTB; the opposite effect is observed for GRC. This phenomenon which is usually not observed for similar FD-SOI MOSFET devices can be explained by the presence of massive series resistance which is increasing when taking down the temperature due to a freeze-out of the dopants. We conclude that, for GRC device, the series resistance extraction is more physically coherent than the electron mobility one for moderate transverse field. Without the $Y$-function analysis we would have concluded an incoherent low value and behavior of the electron mobility for this device. Finally, this case study may be useful for the scientific community as guidance to interpret nonconventional electrical characteristics of nanoscale devices.

\section{Conflict of Interests}

The authors have no conflict of interests associated with this paper.

\section{Acknowledgment}

The authors would like to acknowledge Albert Ciprut for the TCAD simulation work.

\section{References}

[1] G. Ghibaudo, "New method for the extraction of MOSFET parameters," Electronics Letters, vol. 24, no. 9, pp. 543-545, 1988.

[2] A. Ortiz-Conde, F. J. García Sánchez, J. J. Liou, A. Cerdeira, M. Estrada, and Y. Yue, "A review of recent MOSFET threshold voltage extraction methods," Microelectronics Reliability, vol. 42, no. 4-5, pp. 583-596, 2002.

[3] C. Mourrain, B. Cretu, G. Ghibaudo, and P. Cottin, "New method for parameter extraction in deep submicrometer MOSFETs," in Proceedings of the International Conference on Microelectronic Test Structures (ICMTS '00), pp. 181-186, IEEE, March 2000.

[4] D. Fleury, A. Cros, H. Brut, and G. Ghibaudot, "New Yfunction-based methodology for accurate extraction of electrical parameters on nano-scaled MOSFETs," in Proceedings of the IEEE Conference on Microelectronic Test Structures (ICMTS '08), pp. 160-165, IEEE, Edinburgh, UK, March 2008.

[5] A. Cros, S. Harrison, R. Cerutti, P. Coronel, G. Ghibaudo, and H. Brut, "New extraction method for gate bias dependent series resistance in nanometric double gate transistors," in Proceedings of the IEEE International Conference on Microelectronic Test Structures (ICMTS '05), vol. 18, pp. 69-74, IEEE, April 2005.

[6] D. Fleury, A. Cros, G. Bidal, J. Rosa, and G. Ghibaudo, "A new technique to extract the source/drain series resistance of MOSFETs," IEEE Electron Device Letters, vol. 30, no. 9, pp. 975977, 2009.

[7] C. Diouf, A. Cros, S. Monfray et al., "'Y function' method applied to saturation regime: apparent saturation mobility and saturation velocity extraction," Solid-State Electronics, vol. 85, pp. 12-14, 2013.

[8] D. Fleury, A. Cros, G. Bidal, H. Brut, E. Josse, and G. Ghibaudo, "A new technique to extract the gate bias dependent S/D series resistance of sub-100 nm MOSFETs," in Proceeding of the International Symposium on VLSI Technology, Systems, and Applications (VLSI-TSA '09), pp. 109-110, April 2009.

[9] G. Ghibaudo and F. Balestra, "Modelling of ohmic MOSFET operation at very low temperature," Solid-State Electronics, vol. 31, no. 1, pp. 105-108, 1988.

[10] A. Emrani, G. Ghibaudo, F. Balestra, B. Piot, V. Thirion, and A. Straboni, "Low temperature electrical characterization of metalnitrided oxide-silicon field effect transistors," Journal of Applied Physics, vol. 73, no. 10, pp. 5241-5253, 1993.

[11] F. Balestra and G. Ghibaudo, "Brief review of the MOS device physics for low temperature electronics," Solid-State Electronics, vol. 37, no. 12, pp. 1967-1975, 1994.

[12] G. Ghibaudo and F. Balestra, "Low temperature characterization of silicon CMOS devices," Microelectronics Reliability, vol. 37, no. 9, pp. 1353-1366, 1997.

[13] C.-L. Huang and G. S. Gildenblat, "Measurements and modeling of the n-channel MOSFET inversion layer mobility and device characteristics in the temperature range 60-300 K," IEEE Transactions on Electron Devices, vol. 37, no. 5, pp. 1289-1300, 1990.

[14] I. M. Hafez, A. Emrani, G. Ghibaudo, and F. Balestra, "Modelling of electron mobility in silicon MOS inversion and accumulation layers at liquid helium temperature," Electronics Letters, vol. 26, no. 19, pp. 1633-1635, 1990.

[15] A. Emrani, F. Balestra, and G. Ghibaudo, "On the understanding of electron and hole mobility models from room to liquid helium temperatures," Solid-State Electronics, vol. 37, no. 10, pp. 1723-1730, 1994.

[16] I. M. Hafez, F. Balestra, and G. Ghibaudo, "Characterization and modeling of silicon metal-oxide-semiconductor transistors at liquid-helium temperature: influence of source-drain series resistances," Journal of Applied Physics, vol. 68, no. 7, pp. 3694$3700,1990$.

[17] A. Emrani, F. Balestra, and G. Ghibaudo, "Generalized mobility law for drain current modeling in Si MOS transistors from liquid helium to room temperatures," IEEE Transactions on Electron Devices, vol. 40, no. 3, pp. 564-569, 1993.

[18] G. Ghibaudo and F. Balestra, "A method for MOSFET parameter extraction at very low temperature," Solid-State Electronics, vol. 32, no. 3, pp. 221-223, 1989.

[19] F. Balestra and S. Cristoloveanu, "Special mechanisms in thinfilm SOI MOSFETs," Microelectronics Reliability, vol. 37, no. 9, pp. 1341-1351, 1997.

[20] F. Balestra and G. Ghibaudo, Device and Circuit Cryogenic Operation For Low Temperature Electronics, chapter 3, Springer Science, Berlin, Germany, 2001. 
[21] G. Groeseneken, J.-P. Colinge, H. E. Maes, J. C. Alderman, and S. Holt, "Temperature dependence of threshold voltage in thinfilm SOI MOSFET"s," IEEE Electron Device Letters, vol. 11, no. 8, pp. 329-331, 1990.

[22] N. Goel and A. Tripathi, "Temperature effects on threshold voltage and mobility for partially depleted SOI MOSFET," International Journal of Computer Applications, vol. 42, no. 21, pp. 56-58, 2012.

[23] J. Jomaah, G. Ghibaudo, and F. Balestra, "Analysis and modeling of self-heating effects in thin-film SOI MOSFETs as a function of temperature," Solid-State Electronics, vol. 38, no. 3, pp. 615618, 1995.

[24] E. Simoen, C. Claeys, and J. A. Martino, "Parameter extraction of MOSFETs operated at low temperature (WOLTE 2)," Journal de Physique IV, vol. 6, no. C3, pp. C3-29-C3-42, 1996, Proceedings of the 2nd European Workshop on Low Temperature Electronics.

[25] G. Ghibaudo and F. Balestra, "Characterization and modeling of silicon CMOS transistor operation at low temperature," Journal de Physique IV, vol. 6, no. C3, pp. C3-3-C3-11, 1996, Proceedings of the 2nd European Workshop on Low Temperature Electronics (WOLTE 2).

[26] A. Karsenty and A. Chelly, "A comparative study of electrical transport phenomena in ultrathin versus nanoscale SOI MOSFETs devices," International Journal of Electrical Science and Engineering, vol. 7, no. 1, pp. 1243-1247, 2013.

[27] A. Karsenty and A. Chelly, "Modeling of the channel thickness influence on electrical characteristics and series resistance in gate-recessed nanoscale SOI MOSFETs," Active and Passive Electronic Components, vol. 2013, Article ID 801634, 10 pages, 2013.

[28] A. Karsenty and A. Chelly, "Influence of series massive resistance on capacitance and conductance characteristics in gaterecessed nanoscale SOI MOSFETs," Active and Passive Electronic Components, vol. 2013, Article ID 813518, 11 pages, 2013.

[29] A. Karsenty and A. Chelly, "Comparative study of NSB and UTB SOI MOSFETs characteristics by extraction of series resistance," Solid-State Electronics, vol. 91, pp. 28-35, 2014.

[30] A. Karsenty and A. Chelly, "Application, modeling and limitations of Y-function based methods for massive series resistance in nanoscale SOI MOSFETs," Solid-State Electronics, vol. 92, pp. 12-19, 2014.

[31] http://www.crosslight.com/ .

[32] A. Karsenty and A. Chelly, "Comparative study of NSB and UTB SOI MOSFETs characteristics by extraction of series resistance," Solid-State Electronics, vol. 91, pp. 28-35, 2014.

[33] T. Ernst, S. Cristoloveanu, G. Ghibaudo et al., "Ultimately thin double-gate SOI MOSFETs," IEEE Transactions on Electron Devices, vol. 50, no. 3, pp. 830-838, 2003.

[34] T. Elewa, F. Balestra, S. Cristoloveanu et al., "Performance and physical mechanisms in SIMOX MOS transistors operated at very low temperature," IEEE Transactions on Electron Devices, vol. 37, no. 4, pp. 1007-1019, 1990.

[35] Y. Omura, S. Horiguchi, M. Tabe, and K. Kishi, "Quantummechanical effects on the threshold voltage of ultrathin-SOI nMOSFET"s," IEEE Electron Device Letters, vol. 14, no. 12, pp. 569-571, 1993.

[36] W.-J. Cho, S. Lee, M. Jang, S. Maeng, T. W. Kang, and K. W. Park, "Characteristics of nanowire SOI n-MOSFET with a gate length of $50 \mathrm{~nm}$ and a channel width of $100 \mathrm{~nm}$," Journal of the Korean Physical Society, vol. 41, no. 4, pp. 509-513, 2002.
[37] S.-I. Takagi, A. Toriumi, M. Iwase, and H. Tango, "On the universality of inversion layer mobility in Si MOSFET"s: part Ieffects of substrate impurity concentration," IEEE Transactions on Electron Devices, vol. 41, no. 12, pp. 2357-2362, 1994.

[38] P. K. McLarty, S. Cristoloveanu, O. Faynot, V. Misra, J. R. Hauser, and J. J. Wortman, "A simple parameter extraction method for ultra-thin oxide MOSFETs," Solid-State Electronics, vol. 38, no. 6, pp. 1175-1177, 1995.

[39] G. Ghibaudo, M. Mouis, L. Pham-Nguyen et al., "Electrical transport characterization of nano CMOS devices with ultrathin silicon film," in Proceeding of the 9th International Workshop on Junction Technology (IWJT '09), pp. 58-63, Kyoto, Japan, June 2009.

[40] B. J. Sheu, C. Hu, P. K. Ko, and F.-C. Hsu, "Source-and-drain series resistance of LDD MOSFET's," IEEE Electron Device Letters, vol. 5, no. 9, pp. 365-367, 1984.

[41] C. Y. Hwang, T.-C. Kuo, and J. C. S. Woo, "Extraction of gate dependent source/drain resistance and effective channel length in MOS devices at $77 \mathrm{~K}$,' IEEE Transactions on Electron Devices, vol. 42, no. 10, pp. 1863-1865, 1995.

[42] G. Ghibaudo, F. Balestra, and A. Emrani, "A survey of MOS device physics for low temperature electronics," Microelectronic Engineering, vol. 19, no. 1-4, pp. 833-840, 1992. 

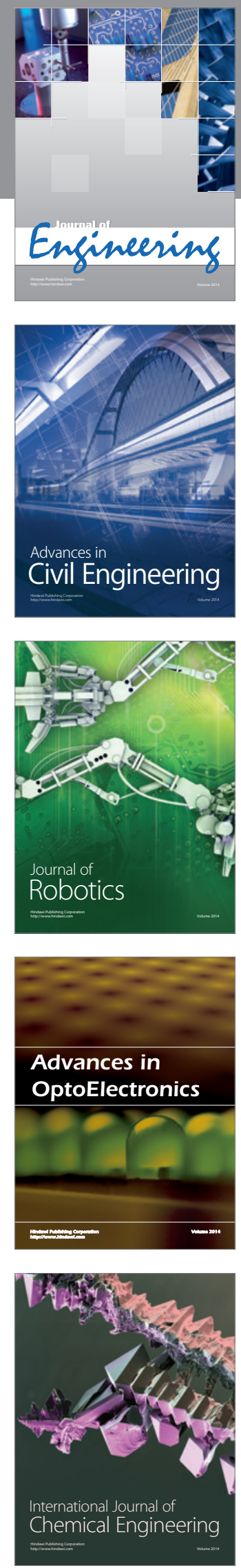

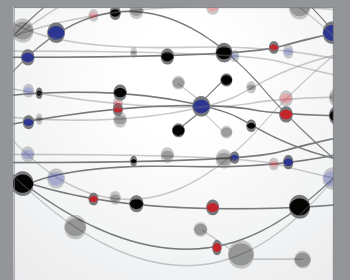

The Scientific World Journal
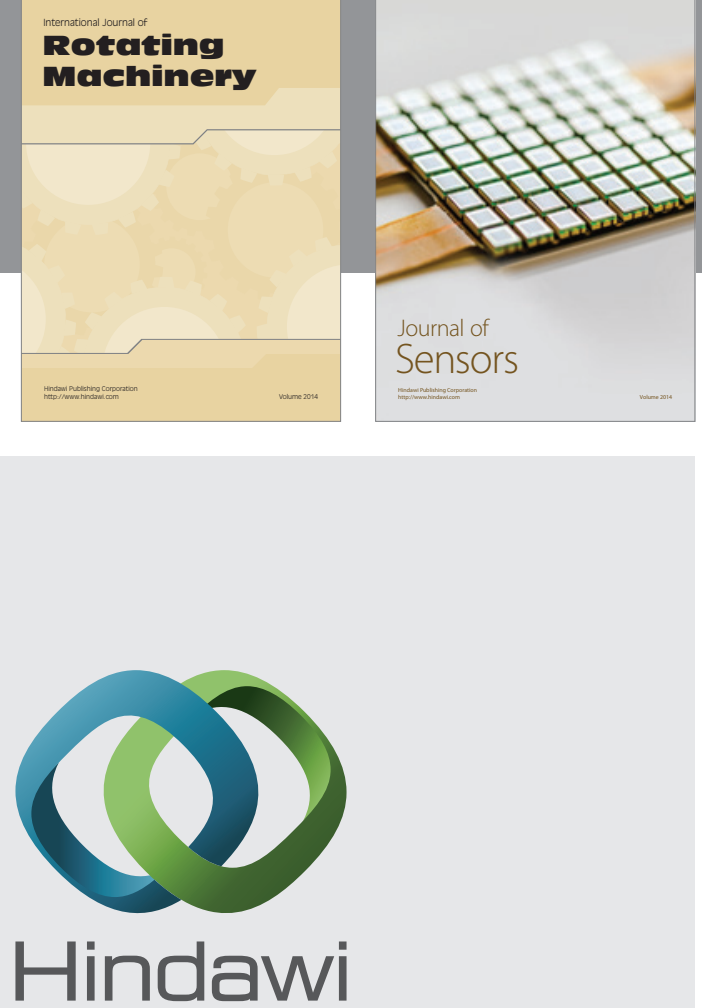

Submit your manuscripts at http://www.hindawi.com
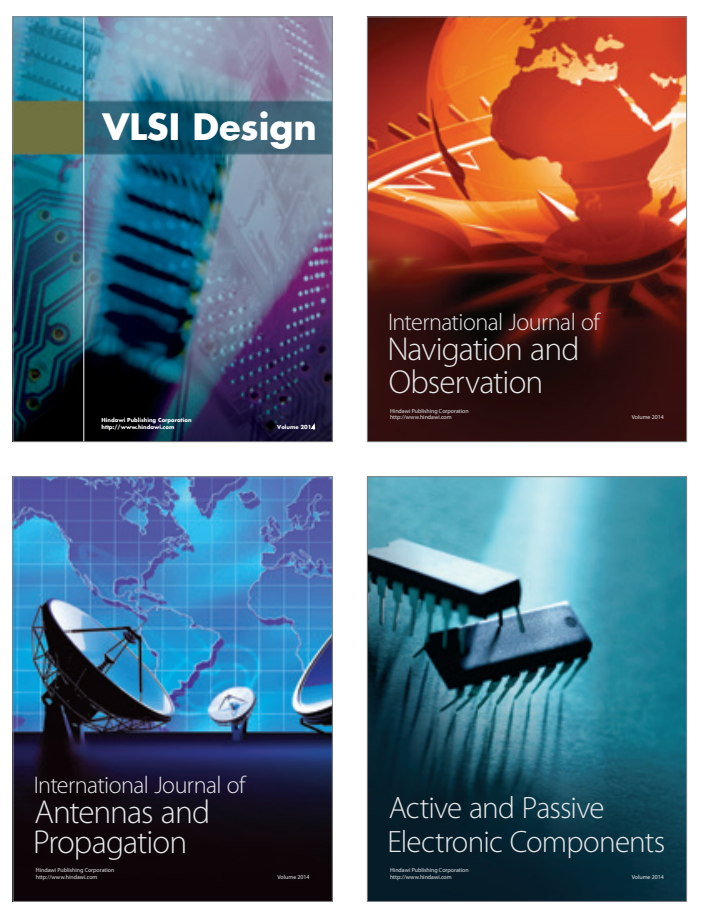
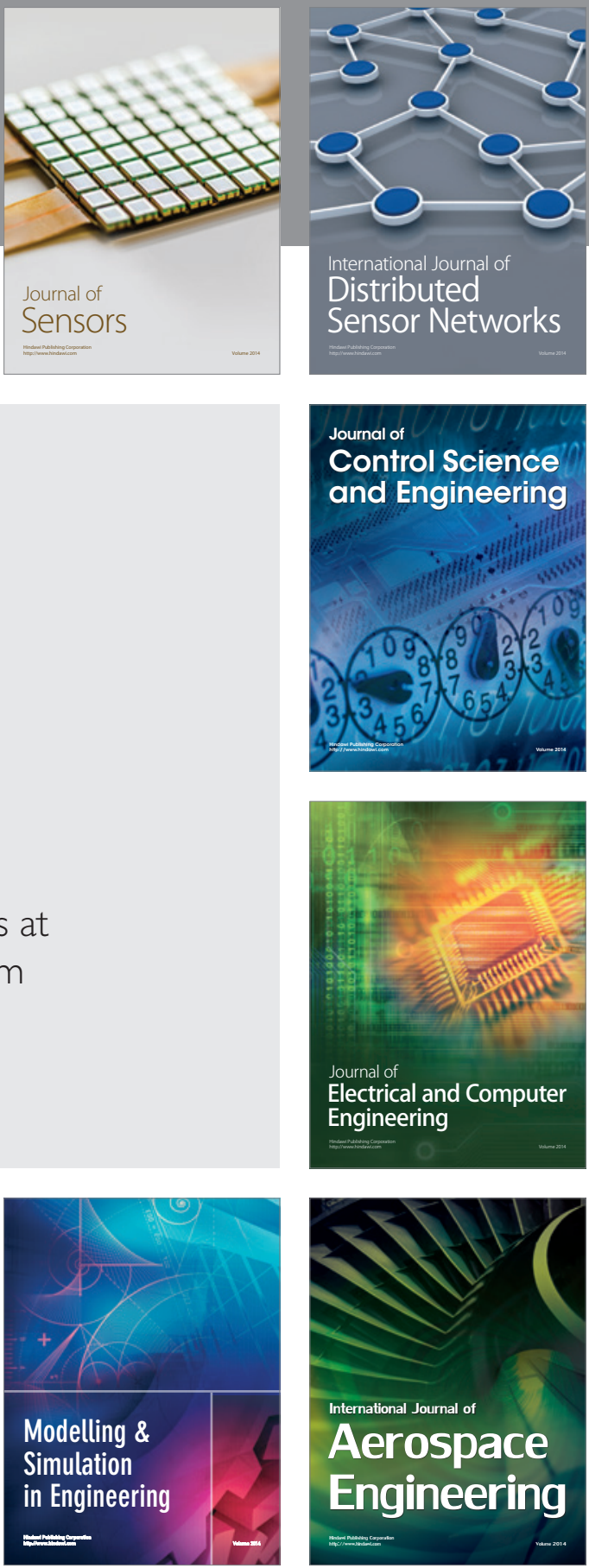

Journal of

Control Science

and Engineering
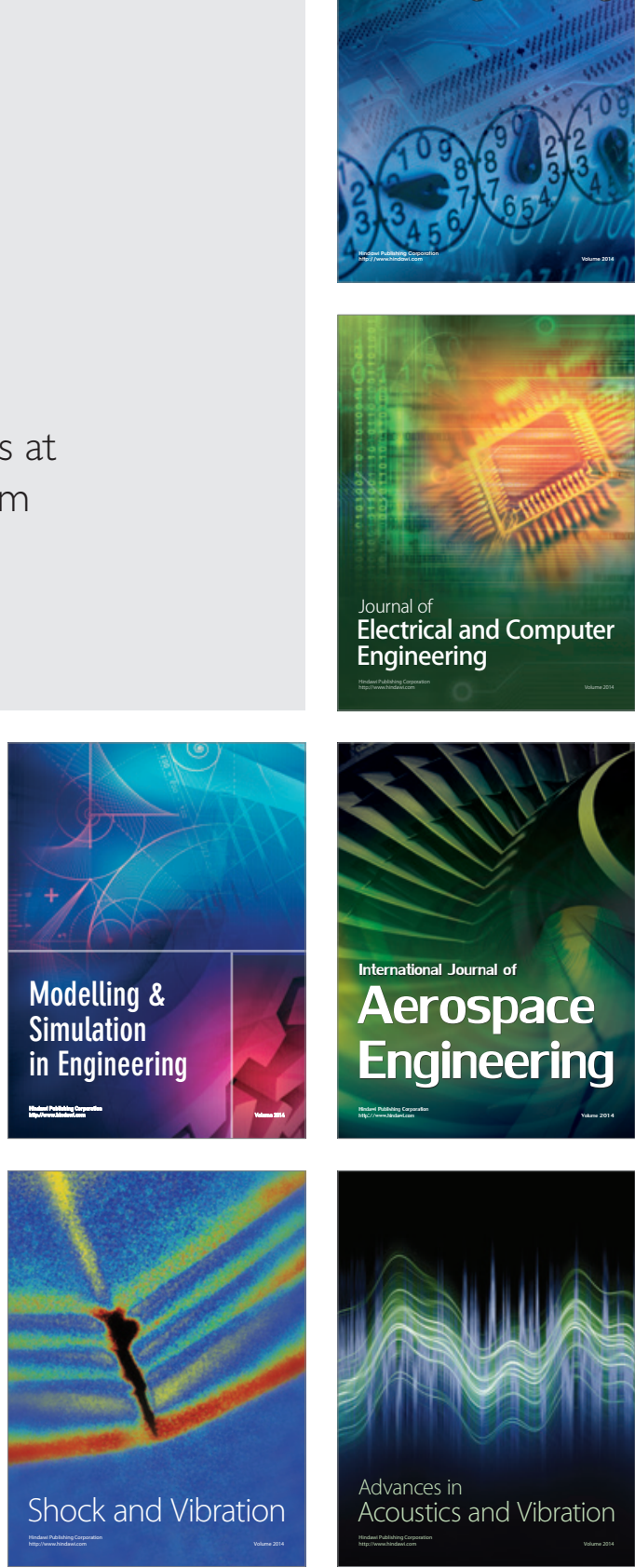